Revista Aspas

ppgac - USP

Artigo

\title{
PERFORMANCE, IMAGEM E DRAMA NA CENA DE CHRISTIANE JATAHY
}

\author{
PERFORMANCE, IMAGE AND DRAMA IN CHRISTIANE \\ JATAHY'S SCENE
}

\section{PERFORMANCE, IMAGEN Y DRAMA EN LA ESCENA DE CHRISTIANE JATAHY}

\author{
João Bernardo Fernandes Caldeira
}

João Bernardo Fernandes Caldeira

Doutorando em Artes Cênicas na ECA-USP, é diretor, autor, produtor e professor teatral. Mestre em Artes da Cena, graduado em Comunicação e Direção Teatral, pela ECO-UFRJ.

Especialização em Gestão e Políticas Culturais pelo Itaú Cultural/Universidade de Girona. Como jornalista cultural, é colaborador do jornal Valor Econômico. 


\section{Resumo}

Examinaremos alguns dos procedimentos e propostas formuladas pela encenadora Chistiane Jatahy, de modo a assinalar movimentos da cena contemporânea de ruptura com o texto dramático e abertura para outros elementos imagéticos, simbólicos, visuais. De viés processual, transitório e performativo, o seu campo de pesquisa investiu-se do desejo de superar a separação entre arte e vida, como forma de desestabilizar os elos da narrativa dramática. Por meio de autores como Lehman, Pavis e Artaud, analisaremos os hibridismos de linguagem e proposições de uma cena situada numa zona de concomitância entre fragmentação e homogeneidade, presença e representação, performance e teatro.

Palavras-chave: Teatro contemporâneo, Teatro performativo, teoria teatral

\section{Abstract}

We will examine some of the procedures and proposals formulated by the director Chistiane Jatahy, to indicate movements in the contemporary scene that break with the dramatic text and openness to other imaginary, symbolic, visual elements. With a procedural, transitory and performative bias, his field of research has invested in the desire to overcome the separation between art and life, as a way of destabilizing the links of the dramatic narrative. Through Lehman, Pavis and Artaud, we will analyze the hybridizations of language and propositions of a scene located in an area of concomitance between fragmentation and homogeneity, presence and representation, performance and theater.

Keywords: Contemporary theater, Performative theater, theatrical theory

\section{Resumen}

Examinaremos algunos de los procedimientos y propuestas formulados por la directora Chistiane Jatahy, para señalar movimientos de la escena contemporánea de ruptura con el texto dramático y apertura a otros elementos imaginarios, simbólicos, visuales. Con un sesgo procedimental, transitorio y performativo, su campo de investigación se ha invertido en el deseo de superar la separación entre arte y vida, como una forma de desestabilizar los vínculos de la narrativa dramática. A través de Lehman, Pavis y Artaud, analizaremos las hibridaciones de lenguaje y proposiciones de una escena ubicada en una zona de concomitancia entre fragmentación y homogeneidad, presencia y representación, performance y teatro.

Palabras clave: Teatro contemporáneo, Teatro performativo, Teoría teatral 
O surgimento do teatro e do encenador modernos, no final do século $\mathrm{XIX}$, liberou o texto dramático de algumas de suas amarras totalizantes, ao desestabilizar a figura do autor. Até então, tido como universal, o texto dramático não era problematizado como um emaranhado de múltiplas camadas de leitura e interpretação. Assim, o processo de montagem de um texto teatral espelhava uma interpretação fixa e unívoca. Podemos dizer que Antonin Artaud foi um dos que denunciaram essa relação de solapamento dos sentidos sobre o texto, a qual descreveu como "tirania da palavra" preconizada pelo "Deus-Criador", isto é, o autor (DERRIDA, 2009). Também Foucault (2001) discorreu sobre o regime de poder por trás da "função-autor", e Roland Barthes assinalou que a liberação dos sentidos e devires de uma obra exigiria a "morte do autor" (2004).

O que Artaud almejou combater foram as desmedidas proporções assumidas pelo poder da palavra e do texto, que o levam a propor o parricídio contra o detentor abusivo do logos, o pai, a escravização do ator, a relação imitativa da arte e a separação entre plateia e palco (DERRIDA, 2009, p. 151159). A discussão incentiva a revisão do estatuto do texto dramático e do viés textocêntrico e estimula investigações sobre corpo, cena e a própria palavra. Restaurar a cena implicaria, portanto, na destruição da tirania da palavra e na reconstituição de sua natureza rearticulada como gesto, como grito, ou, como chamou Artaud, como Teatro da Crueldade. No teatro moderno, portanto, a figura do encenador libera a cena a explorar novas camadas de sentido e visualidades. $O$ encenador passa a ser responsável por assinar essa visão singular, e não mais universal, construída a partir de um determinado ponto de vista.

A proeminência e controle sobre o dispositivo teatral passaria a ser exercida, portanto, pelo encenador. Seria necessário, outra vez, explodir as linhas de fuga de modo a eclodir o fechamento propiciado pela entronização do encenador. Sob este contexto que surgem trabalhos dispostos a romper os limites entre performance e teatro, espectador e cena, ficção e realidade, como é o caso dos espetáculos e formulações da diretora Chistiane Jatahy, que nos dispomos a analisar. 
Sua fase mais autoral tem início em 2004, com a peça Conjugado, que inaugura a trilogia completada por $A$ falta que nos move (2005) e Corte seco (2010). Com foco na solidão feminina, o monólogo Conjugado foi construído com base em entrevistas com pessoas que moravam sozinhas, no Rio de Janeiro. Além de utilizar dados reais para constituir uma narrativa ficcional, Jatahy explorou também aquela que se tornaria outra marca de sua trajetória: a relação entre audiovisual e teatro. $O$ cenário da peça traz uma televisão, que transmite a programação ao vivo. Ao final do espetáculo, diversos monitores de TV transmitem um documentário sobre solidão, a partir do material coletado durante o processo.

As fronteiras entre a ficção e a realidade são investigadas ainda mais a fundo em $A$ falta que nos move (2005), que serviria de base para um filme documentário. Em cena, um grupo de atores, que utiliza seus próprios nomes, espera um último ator que estaria atrasado. Instaura-se a sensação de que a situação fugiu do controle. Em uma apresentação em Berlim, um espectador abandonou o teatro, ofendido com a falta de profissionalismo. Enquanto aguarda, o elenco janta e bebe vinho, trazendo ao ato de espera novas camadas performativas. "A bebida provocava uma alteração nos estados dos atores, na realidade e também na ficção e, com isso, as relações ficavam extremadas e os conflitos ganhavam força", afirma a diretora (JATAHY, 2009).

Lançado em 2009, o filme $A$ falta que nos move também embaralha as fronteiras entre documentário e ficção. Os atores estão em uma casa - da própria Jatahy - com o objetivo de preparar um jantar, na véspera do Natal, para uma pessoa que nunca chega. Logo no início do trabalho, a equipe discute as melhores opções de direção. As intervenções do cinegrafista e da diretora junto ao elenco são compartilhadas com o espectador, como materiais inerentes à proposta: "Meu desafio é testar o limite entre a realidade e a ficção, entre o que é para ser visto e o que não, o que é construção cinematográfica e o que é espontâneo", afirmou a diretora, em entrevista na época do lançamento do filme (JATAHY, 2011). Em seu website, ela explica a dinâmica de construção do longa-metragem: 


\begin{abstract}
Filmamos na véspera do Natal - da noite do dia 23 de dezembro à manhã do dia 24 - um Natal de amigos íntimos, em que memórias e revelações vêm à tona. Foram 13 horas de filmagem que resultaram em 39 horas de material bruto. (...) A filmagem foi contínua e o filme parece um plano sequência, mas na verdade é uma grande colcha de retalhos que recria uma ideia de realidade. Um exercício de dobras sobre si mesmo, onde nem tudo é realmente como parece (JATAHY, 2018).
\end{abstract}

Durante seis meses, os atores ensaiaram seus papéis. Terminados os processos, o filme foi rodado em treze horas seguidas de filmagens, sem cortes ou interrupções, num único espaço-locação. "Depois da décima hora, eles param um pouco de atuar, oferecendo novos estágios emocionais e gerando uma mistura de verdade e performance" afirma Jatahy (2012).

A palavra mais importante para mim é o entre. Para mim só existe algo no momento presente. Quando o ator está mais ligado no outro do que nele, não existe interpretação, não existe personagem, e não precisa mais de dramaturgia, porque você está dentro da dramaturgia. Falar sobre o presente é fácil, difícil é estar nele (informação verbal ${ }^{1}$ ).

Antes da gravação de $A$ falta que nos move foram criados dez dispositivos a estabelecer as regras do jogo, ou o programa performativo a ser cumprido, entre eles: o uso de três câmeras simultâneas em uma única locação; a direção durante a filmagem por mensagens de texto; os atores seguiriam seus roteiros, mas não teriam conhecimento de todo o script uns dos outros; o grupo executa ações reais como comer, cozinhar, beber e ir ao banheiro; algumas das histórias narradas são reais; e ninguém pode deixar a casa.

Essa lista pré-estabelecida de regras nos remete ao Manifesto Dogma 95, uma influência assumida no trabalho de Jatahy. Lançado em 1995 pelos cineastas dinamarqueses Thomas Vinterberg e Lars von Trier, esse movimento também estabelecia normas no trato com os materiais gravados, evitando efeitos de edição, cortes excessivos, trilhas gravadas, etc. Também não eram permitidos deslocamentos temporais ou geográficos, como que

\footnotetext{
${ }^{1}$ Na disciplina “Arte e Cena”, ministrada pelo professor André Parente, no Programa de PósGraduação em Artes da Cena, em 12 de maio de 2014.
} 
respeitando, poderíamos assinalar, as unidades aristotélicas de tempo e de lugar.

Está em jogo, portanto, tanto no Dogma quanto no trabalho de Jatahy, a intenção de fugir do excesso de interferências artificiais (ou dramáticas) de edição, fotografia, cenografia, direção, etc. Buscava-se uma abordagem do real de modo a incorporá-lo na ficção e a registrá-lo tal como manifestado no ato de filmagem. Por meio deste programa performativo, diríamos que estes procedimentos possuem uma dupla capacidade de registrar tanto uma sequência de instantes presentes, de acontecimentos, como também o seu devir-outro, aquilo que se tornará e que ainda não somos capazes de enxergar (DELEUZE, 1996, p.5).

A relação entre vídeo e teatro no trabalho de Jatahy extrapola a cena e ganha o espaço urbano no espetáculo Corte seco, a partir de câmeras de segurança instaladas na rua. Os atores interagem com transeuntes, sob o mesmo princípio da performance, enquanto, no interior do teatro, a plateia assiste às imagens produzidas. Os atores passam a agir como performers, verdadeiros criadores em cena, em vez de representarem papéis fictícios. A desconstrução da figura do encenador moderno passa, necessariamente, por essa troca de maior horizontalidade entre os diversos criadores a participarem do processo de encenação.

Assim, Jatahy e sua equipe artística acabam por oferecer um mosaico de combinações e uma flutuação de fronteiras, composta pela mistura da realidade captada em tempo real (transeuntes, carros, rua), da linguagem do vídeo e da atuação performática dos atores. De forma análoga às bruscas interrupções que acontecem na vida, como um acidente, um crime ou um fato banal, Jatahy participa da cena promovendo cortes bruscos na narrativa teatral, editando ao vivo parte do espetáculo, alterando a ordem das cenas, como um exercício de metalinguagem, que se modifica a cada sessão. Ao público são reveladas as estratégias performativas e dramatúrgicas do espetáculo.

Em 2011, Jatahy inaugura nova trilogia. Em Julia, adaptação do texto Senhorita Julia, escrito em 1888 pelo sueco August Strindberg, a diretora mais uma vez investiga o entrelaçamento das linguagens teatral e cinematográfica, 
ao apresentar, simultaneamente, a mesma cena nas formas teatral e cinematográfica. A intenção não é comentar este clássico do teatro, mas revivê-lo: "O desafio era: como invadir este clássico com tamanho grau de atualidade? De que maneira posso fazer com que pareça real? Não é desconstrução, mas atualização" (informação verbal²).

No telão, cenas pré-filmadas se misturam a cenas registradas ao vivo durante a própria encenação. Cabe ao espectador selecionar, a cada momento, qual das ações e telas terão a sua atenção. Julia (interpretada por Julia Bernart) é uma menina rica de 17 anos que seduz Jelson (Rodrigo dos Santos), o motorista da família, com quem passa uma noite de sexo e delírio planejando uma fuga redentora que os libertaria de suas vidas e mazelas sociais. Em parte do espetáculo, o público é, de certa maneira, refém do olhar do cameraman, que seleciona as cenas a serem vistas ou "apenas" escutadas.

Durante todo o filme/teatro, o cinegrafista dá aos atores comandos típicos do imaginário da função-direção, como atos de fala: "ação!”, "corta!". Em alguns momentos, o jogo cênico é impulsionado pela interação direta de Julia com o cinegrafista, assumindo-se como atriz e não somente personagem:

\begin{abstract}
O que fica dessa experiência estética é a possibilidade de pensar nos efeitos provocados pelos diversos movimentos $e$ deslocamentos da visão, oscilantes entre a apreciação espaçotemporal da imagem de cinema e a materialidade das atuações ao vivo, nas fraturas que expõem as diferenças sensíveis do aparato técnico do filme e da elaboração do aqui e agora da atuação, que pretendem não deixar a plateia esquecer que está num lugar teatral, zona de conflito por excelência (ALLONSO, 2011).
\end{abstract}

No espetáculo E se elas fossem para Moscou?, baseado no texto As Três Irmãs, de Tchekhov, Jatahy propõe mais uma vez a encenação de um texto clássico do teatro moderno, permeado pela simultaneidade de linguagens. Desta vez, uma escolha decisiva é colocada ao espectador antes mesmo do início da apresentação: é preciso optar se irá assistir à obra no

\footnotetext{
2 Na disciplina “Arte e Cena”, ministrada pelo professor André Parente, no Programa de PósGraduação em Artes da Cena, em 12 de maio de 2014.
} 
espaço cênico ou na sala de projeção (sala de cinema?), onde são transmitidas as imagens captadas ao vivo. Após a temporada de estreia, a diretora passou a apresentar o espetáculo sempre em dose dupla: isto é, a plateia assiste ao trabalho sob os dois pontos de vista, separados por um breve intervalo. Trata-se aqui de um esboço do que faria, anos mais tarde, em Ítaca: dividido em duas arquibancadas frontais - dois pontos de vista, portanto - o público assiste ao espetáculo duas vezes, sob os dois diferentes ângulos de expectação. Em ambos os trabalhos, está em jogo a ideia de que a percepção é sempre multifacetada, instável e incompleta. Atravessada por realidade e ficção, vida e arte, a obra é sempre fruto de movimentos contínuos de construção e desconstrução.

Voltando ao espetáculo E se elas fossem para Moscou?, o público testemunha os bastidores de uma equipe de filmagem e presencia um set no qual o trabalho e movimentação dos atores destinam-se à câmera. Enquanto isso, a plateia da sala de cinema tem acesso às escolhas realizadas pela diretora, que edita e mixa imagens e som durante a apresentação. Assim, diante dessa permanente impossibilidade de inteireza e completude, os espectadores são convidados a assumirem a coautoria da cena. Não é possível delimitar se estão diante de um improviso ensaiado ou de um real encenado, se o espetáculo já decorreu ou se ainda está por começar. É este o lugar do híbrido e do entrelugar, de caráter liminar e intersticial, transitório, instável, temporário e indeterminável.

\begin{abstract}
Fronteiras são zonas de instabilidade, de risco, onde um território avança sobre o outro ultrapassando linhas invisíveis. É justamente na transitoriedade dessas linhas que a minha pesquisa reside. Teatro, vídeo/cinema, ator, personagem, realidade ou ficção extrapolam seus territórios de domínio para se chocarem no espaço da experimentação artística. Tornar híbrido para produzir novas situações e apreensões é o objetivo dos últimos trabalhos que realizei (JATAHY, 2010).
\end{abstract}

É possível apontar, portanto, nesta pesquisa autoral iniciada pela encenadora em 2004, com Conjugado, uma necessidade de produzir territórios limítrofes entre representação e performance, mimese e texto, site specific e devir. O texto da cena e a cena do texto se modificam a cada leitura, a cada ensaio, a cada apresentação, visto que "não nos banhamos jamais 
duas vezes no mesmo rio nem no mesmo texto", observa Patrice Pavis (2012, p.398).

Uma chave para compreender este jogo de infinito tensionamento é perceber esse movimento como próprio das experiências cênicas que, como descreve Christophe Bident, se organizam em torno de polos que se chocam e se impulsionam concomitantemente (2016, p.53). Seria uma cena a conjugar fragmentação e homogeneidade, mundo-mundo e mundo-teatro, em relação de simultaneidade, conflito e justaposição. A impossibilidade de totalizar e fixar formas e afirmações estaria, assim, ligada à sua própria condição de questionar-se permanentemente:

\footnotetext{
A encenação que desconstrói seu objeto interrogando seu funcionamento, da mesma forma que sua proveniência, não renuncia à virtude crítica da representação teatral, à sua faculdade de interrogar e contestar o real (PAVIS, 2012, p.230).
}

Uma maneira de pensar esta cena de viés híbrido seria tomar o conceito de performise, que procura interligar as imbricações e contradições inerentes a esta relação tensionada entre mise-en-scène e performance (PAVIS, 2012 p.39 e p.86). Neste espaço liminar e transitório, podemos pressupor que o texto (ou as palavras ditas em cena) não produz estrutura totalizante. Em vez disso, texto, dramaturgia, atuação, iluminação, direção de arte, etc., fazem parte de uma escritura do acontecimento, que suspende e interroga a narrativa clássica teatral. "O conceito deve dizer o acontecimento, e não mais a essência”, diz Deleuze (1992, p.37). A cena diz aquilo que ela performa, e não mais a representação.

Essa narrativa suspende, portanto, a hierarquização dos recursos teatrais. Naquilo que Hans-Thies Lehmann cunhou chamar de teatro pósdramático, as estruturas narrativas não se relacionam mais por hipotaxe e subordinação, mas por parataxe, interligação:

Com a parataxe do teatro pós-dramático os elementos não mais se concatenam de modo inequívoco.(...) Pode-se constatar um tratamento não hierárquico dos signos que visa a uma percepção sinestética e rejeita uma hierarquia estabelecida, que privilegia a linguagem, o modo de falar e o gestual e em que as qualidades visuais, como a experiência arquitetônica do espaço, quando 
chegam a entrar em jogo, figuram como aspectos subordinados. (LEHMANN, 2007, p.143-144).

Assim, o espectador tem diante de si uma encenação onde elementos antes solapados pela hegemonia textual, como os aspectos visuais, imagéticos e simbólicos, passam a multiplicar sentidos, percepções e significados. Uma representação assim emancipada, termo proposto por Rancière, produz um espectador igualmente emancipado, visto que lhe é dada a livre oportunidade de associar, dissociar, traduzir e traçar seu caminho nessa floresta de signos (RANCIÈRE, 2010, p. 20 e 21).

A partir dos anos 60, a ênfase da narrativa teatral desloca-se do ficcional para o seu entrelaçamento com o real. Neste sentido, quando os dispositivos da cena de Jatahy deslocam-se para o próprio ator e seu corpo, para o ambiente real onde se passa a cena, estaria implicada a intenção de esvaziar os estratos dramáticos da encenação. Fischer-Lichte nos aponta que o desaparecimento temporário das figuras dramáticas perturba a ordem representacional, deslocada pela ordem da presença (2013, p.20-22). O seu conceito de multiestabilidade perceptiva procura assinalar, justamente, esse deslocamento contínuo de uma ordem para outra, em permanente estado de instabilidade, liminaridade e passagem. Neste movimento, o espectador tem a oportunidade de perceber que, tanto no teatro quanto no mundo, os acontecimentos são espontâneos, caóticos, imprevisíveis, emergentes e incontroláveis, independentemente de sua vontade.

Situado nestes espaços limítrofes, o encenador contemporâneo deixa de ocupar aquela centralidade própria do teatro moderno, quando era responsável por organizar e formular os sentidos de uma montagem. Sob o conceito de intermedialidade, Patrice Pavis (2012, p. 358) assinala que o encenador contemporâneo é uma espécie de regulador a organizar as situações vivenciadas a partir do processo de ensaios. O seu papel, nos parece, seria intermediar esses tensionamentos entre a obra e os seus processos, entre as utopias e suas contradições, entre a radical dissolução da cena e a sua possibilidade de reconstrução, entre arte política e politização da arte, entre ritual e devir, ética e estética. Também lhe caberia pensar a mediação entre plateia e espetáculo, de forma que esta relação ocorra da 
maneira mais horizontal e ativa possível, como vislumbra Rancière (2010, p. 16 a 19). É sua tarefa manter viva a capacidade de o teatro, por meio do que Lehmann denomina de estética do risco, lidar com afetos extremos, quebrar tabus, violar sentimentos, fazer o espectador deparar-se com a sua própria presença, confrontá-lo com o medo abissal, sem perder o humor e a diversão (2007, p. 427). Afinal, o teatro permanece sendo esse espaço onde as pessoas olham-se e aspiram a esse "segundo sagrado", somente experimentado durante o "silêncio de morte" da plateia (PAVIS, 2012, p. 356).

Talvez devêssemos agora nos perguntar se por trás desse obsessivo desejo de contato com o real não estaria, em alguma medida, a retomada do projeto idealista moderno de aproximação e estetização da vida. Mas essa já é uma outra história.

\section{Referências bibliográficas}

ALLONSO, Pedro. O espaço teatral como zona de conflito estético: crítica do espetáculo Julia, de Christiane Jatahy. [27, nov, 2009] Questão de crítica Revista eletrônica de críticas e estudos teatrais. Disponível em: <http:// www.questaodecritica.com.br/2011/11/o-espaco-teatral-como-zona-de-conflitoestetico/>. Acesso em 12 abril. 2021.

ARTAUD, Antonin. O teatro e seu duplo. São Paulo: Martins Fontes, 2012.

BARTHES, Roland. "A morte do autor". In: O rumor da língua. São Paulo: Martins Fontes, 2004.

BIDENT, Christophe. O teatro atravessado. Art Research Journal - ARJ, v.3, n.1, 2016. Disponível em:

https://periodicos.ufrn.br/artresearchjournal/article/view/8504/6807

DELEUZE, Gilles. O que é um dispositivo? In: O mistério de Ariana. Lisboa: Ed. Vega - Passagens, 1996.

DELEUZE, Gilles. Conversações. Rio de Janeiro: Graal, 1992.

DERRIDA, Jacques. A escritura e a diferença. São Paulo: Perspectiva, 2009.

FISCHER-LICHTE, Erika. Realidade e ficção no teatro contemporâneo. Revista Sala Preta, São Paulo, v. 13, N. 2, 2013. Disponível em:

http://www.revistas.usp.br/salapreta/article/view/69073/71517 
FOUCAULT, Michel. O que é um autor? In: Ditos e Escritos: Estética - literatura e pintura, música e cinema (vol. III). Rio de Janeiro: Forense Universitária, 2001. p. 264-298

JATAHY, Christiane. A falta que nos move. [2009] Site

http://christianejatahy.com.br. Disponível em:

<http://christianejatahy.com.br/project/a-falta-que-nos-move>. Último acesso em 12 de abril de 2021.

\section{A essência do teatro inspira o longa A Falta que nos}

Move. [24 out. 2009]. In: entrevista concedida a Ubiratan Brasil. Disponível em: <http://christianejatahy.com.br/afaltaquenosmove/?p=247>. Último acesso em 12 de abril, 2012.

Por mensagem de texto, Christiane Jatahy dirige atores confinados numa casa. [10 set. 2012]. In: entrevista concedida a Paulo Henrique Silva. Hoje em dia. Disponível em:

<https://www.hojeemdia.com.br/acervo/2.694/por-mensagem-de-texto-christianejatahy-dirige-atores-confinados-numa-casa-1.35974>. Último acesso em 12 abril, 2021.

Artista na cidade: as escolhas de Christiane Jatahy.

[Nov, 2018]. Disponível em:

$<$ https://ciclosdacinemateca.wordpress.com/2018/11/06/artista-na-cidade-asescolhas-de-christiane-jatahy/>. Último acesso em 12 abril, 2021.

Fronteira e instabilidade. [2010] Site Tempo Festival.

<https://tempofestival.com.br/simultaneo/fronteira-e-instabilidade/>. Último acesso:

12 de abril, 2021.

LEHMANN, Hans-Thies. Teatro Pós-Dramático. São Paulo: Cosac Naify, 2007.

PAVIS, Patrice. A encenação contemporânea. Origens, tendências,

perspectivas. São Paulo: Perspectiva, 2012.

RANCIÈRE, Jacques. O espectador emancipado. Lisboa, Orfeu Negro, 2010. 